\title{
Comparative performance of cement and metakaolin based-geopolymer blocks for strontium immobilization
}

\author{
Qinwen TAN ${ }^{1}$, Na $\mathbf{L I}^{1}$, Zhonghui XU ${ }^{1, \dagger}$, Xiaoyue CHEN $^{2}$, Xi PENG ${ }^{1}$, Qin SHUAI ${ }^{2}$ and Zhengzhen YAO ${ }^{2}$ \\ ${ }^{1}$ Key Laboratory of Solid Waste Treatment and Resource Recycle, Ministry of Education, \\ Southwest University of Science and Technology, Mianyang 621010, Sichuan, Peoples R China \\ ${ }^{2}$ Non-Coal Mine Safety Technology Key Laboratory of Sichuan Province Colleges and Universities, \\ Southwest University of Science and Technology, Mianyang 621010, Sichuan, Peoples R China
}

\begin{abstract}
This paper presents the comparative performance of ordinary Portland cement and metakaolin-based geopolymer blocks for strontium immobilization. The geopolymer solidified blocks had better leaching resistance in deionized water, sulfuric acid, magnesium sulfuric and acetic acid buffer solutions than the cemented blocks. Meanwhile, the geopolymer solidified blocks exhibited lower compressive strength loss after freeze-thaw cycles and high-temperature tests. The more dense and compact structure of the geopolymer specimens is more beneficial for the retention of the strontium radionuclide. Most of the strontium radionuclide within the geopolymer and cement solidified blocks may be incorporated into the amorphous gels. It could be concluded that the metakaolin based-geopolymer matrix exhibited much better solidification performance and appeared to be more suitable for radioactive waste immobilization.

(02019 The Ceramic Society of Japan. All rights reserved.
\end{abstract}

Key-words : Geopolymer, Cement, Strontium, Immobilization, Radioactive waste

[Received June 28, 2018; Accepted November 5, 2018]

\section{Introduction}

Nuclear power is the use of nuclear reactions that release nuclear energy to generate heat, which is a great discovery in human history. Nuclear power plants provide approximately $5.7 \%$ of the world's energy and $13 \%$ of the world's electricity, but they also could bring nuclear disasters. The Fukushima nuclear accident which occurred on 11 March 2011 caused severe damage to the nuclear plant and a serious nuclear leak. It is reported that the Fukushima nuclear plant is still leaking in early 2017. The Fukushima nuclear accident always reminds us of a longstanding challenge with the nuclear safety, especially the safe and effective immobilization of nuclear wastes.

Cement-based materials are widely used inert binders for the encapsulation of low and intermediate level radioactive wastes. ${ }^{1,2)}$ Because of the porous structure of hardened cement, the leaching behavior of radionuclides in cement matrices attracts too much attention. ${ }^{2), 3)}$ Many inorganic admixtures, such as zeolites, ${ }^{2), 4)}$ bentonites, ${ }^{5)}$ natural clays ${ }^{3)}$ and rice husk ash ${ }^{6), 7)}$ are adopted to enhance the leaching resistance of cement solidified blocks. However, acid and salt attack could cause dissolution and decalcification of the hardened cement, resulting in significant mechanical strength loss and reduction in the leaching resistance. ${ }^{8), 9)}$

\footnotetext{
Corresponding author: Z. Xu; E-mail: zhonghuixu@163. com
}

Currently, many scholars have reported the application of geopolymer to hazardous wastes immobilization, such as municipal solid waste incinerator fly ash, ${ }^{10)-13)}$ chromite ore processing residue ${ }^{14), 15)}$ and radioactive wastes ${ }^{16), 17)}$ etc. Geopolymer blocks exhibit excellent leaching resistance, owing to their amorphous zeolite-like structure. ${ }^{16), 17)}$ Although the leaching of $\mathrm{Cs}^{+}$from geopolymer waste forms increases as a result of the effect of gamma-ray irradiation on the hardened block, geopolymer is still proven to be effective for radionuclide immobilization. ${ }^{18)}$ Nevertheless, radioactive disintegration would gradually release decay heat and lead to a significant temperature rise of hardened blocks. ${ }^{19), 20)}$ Exposure to high temperture may cause compressive strength loss and internal micro cracking of geopolymer blocks and also influence the leaching resistance. $^{21)-24)}$

Earlier studies have both revealed the disadvantages of ordinary Portland cement and geopolymer materials. Hence, the comparative performance of the cement and geopolymer blocks for radionuclides immobilization needs a further examination. In this work, the performance of the ordinary Portland cement and metakaolin basedgeopolymer (abbreviate to geopolymer) blocks for strontium immobilization was investigated. To be specific, the cumulative fraction leaching concentrations of $90 \mathrm{Sr}^{2+}$ in deionized water, sulfuric acid solution, magnesium sulfate solution and acetic acid buffer solution were measured at specified times within 42 days after standard curing. Thermal stability by way of both freeze-thaw and 
high-temperature performance was also given full consideration.

\section{Materials and methods}

\subsection{Materials}

The sodium silicate solution (molar mass ratio $\mathrm{SiO}_{2} /$ $\mathrm{Na}_{2} \mathrm{O}=3.3,26$ wt $\% \mathrm{SiO}_{2}, 8.2 \mathrm{wt} \% \mathrm{Na}_{2} \mathrm{O}$ ) was obtained from Guangzhou Huixin Chemical Industry Co., Ltd. (Guangzhou, China) and adjusted by a certain amount of sodium hydroxide (analytical reagent grade) to make a solution with a modulus (i.e. molar mass ratio $\mathrm{SiO}_{2} /$ $\mathrm{Na}_{2} \mathrm{O}$ ) of 0.8 , which was used as the activator in the geopolymerization. The simulated radionuclide, $90 \mathrm{Sr}^{2+}$, in the form of $\mathrm{Sr}\left(\mathrm{NO}_{3}\right)_{2}$ (analytical reagent grade) was provided by Chengdu Kelong Chemical Reagent Factory (Sichuan, China).

Metakaolin was prepared by calcining kaolinite (Shanghai, China) at $800^{\circ} \mathrm{C}$ for $2 \mathrm{~h}$. The ordinary Portland cement was obtained from Beichuan Sixing Cement Co., Ltd. (Sichuan, China). Table 1 presents the chemical compositions of metakaolin and cement.

\subsection{Sample preparation}

$\mathrm{Sr}\left(\mathrm{NO}_{3}\right)_{2}$ was first dissolved in deionized water to form a homogeneous solution, and then mixed with metakaolin or cement. The percent of the simulated radionuclide $90 \mathrm{Sr}^{2+}$ in the solidified blocks was kept at $0.62 \%$. Geopolymer pastes were prepared with metakaolin, water and water glass at the mass ratio of 1:0.5:0.8. Cement was also used to prepare an additional solidification matrix according to a fixed mass ratio (cement:water $=1: 0.3$ ). The slurries were cast into $20 \mathrm{~mm}$ cube molds and vibrated for $10 \mathrm{~min}$ to remove entrained air bubbles. Subsequently, the molds were sealed with polyethylene film and kept in a standard curing box at $25 \pm 0.5^{\circ} \mathrm{C}$ with humidity of $90 \pm 1 \%$ under ambient pressure. After $24 \mathrm{~h}$, the samples were demolded and kept at room temperature without the polyethylene film for a further 27 days.

The geopolymer and cement hardened blocks without $\mathrm{Sr}\left(\mathrm{NO}_{3}\right)_{2}$ addition (abbreviate to hardened blocks) were also prepared according to the same procedure.

\subsection{Static leaching tests}

Static leaching tests for solidified blocks of strontium radionuclide were conducted in four different extraction solutions, including deionized water, sulfuric acid solution $(\mathrm{pH}=1)$, magnesium sulfuric solution (5 wt \% $\left.\mathrm{MgSO}_{4}\right)$

Table 1. Chemical compositions of metakaolin and cement

\begin{tabular}{ccc}
\hline Component & Metakaolin & Cement \\
\hline $\mathrm{SiO}_{2}$ & 54.25 & 29.89 \\
$\mathrm{Al}_{2} \mathrm{O}_{3}$ & 43.92 & 8.15 \\
$\mathrm{CaO}$ & 0.13 & 49.82 \\
$\mathrm{Fe}_{2} \mathrm{O}_{3}$ & 0.39 & 4.04 \\
$\mathrm{Na}_{2} \mathrm{O}$ & 0.14 & 0.59 \\
$\mathrm{~K}_{2} \mathrm{O}$ & 0.14 & 1.28 \\
$\mathrm{MgO}$ & - & 2.2 \\
$\mathrm{SO}_{3}$ & - & 2.78 \\
Other Oxides & 0.76 & 1.25 \\
\hline
\end{tabular}

and acetic acid buffer solution $(\mathrm{pH}=3.6)$. Each prepared sample was immersed in $200 \mathrm{ml}$ of extraction solution in sealed polyethylene bottles at room temperature. The leachate was sampled and the entire $200 \mathrm{ml}$ solution was replaced with a fresh extraction solution after the 1st, 3rd, 7th, 10th, 14th, 21st, 28th, 35th and 42nd day. After this, the sampled leachate was analyzed using Atomic Absorption Spectroscopy (AA700, PE, US). The cumulative fraction leaching concentration (CFLC) was calculated according to the relevant literature. ${ }^{4)}$

\subsection{Mechanical performance and thermal stability}

\subsubsection{Thermal stability}

The solidification products after standard curing for 28 days were subjected to freeze-thaw cycles. During freezing the samples were kept at $-20^{\circ} \mathrm{C}$ for $3 \mathrm{~h}$ and immediately immersed in water at $15-20^{\circ} \mathrm{C}$ for $4 \mathrm{~h}$ to thaw. Thus a full freeze-thaw cycle was achieved within $7 \mathrm{~h}$. The compressive strength of each matrix was measured after 15 freezethaw cycles.

Geopolymer and cement solidified blocks of strontium radionuclide were heated in a muffle furnace at a heating rate of $5^{\circ} \mathrm{C} / \mathrm{min}$ from room temperature to 600,800 and $1000^{\circ} \mathrm{C}$. After holding for $2 \mathrm{~h}$, the specimens were naturally cooled in the furnace, and the compressive strength gains or losses of the cooled matrices were then determined.

\subsubsection{Mechanical performance}

The compressive strength of the 28 days cured geopolymer and cement blocks were measured with a CMT5504 compressive strength testing apparatus (Shenzhen, China). The specimens after thermal stability tests were also measured. Each result was obtained by taking an average of the results from three specimens.

\subsection{Mineralogical and pore structure characterization}

The mineralogical characterization of the specimens was characterized via X-ray diffraction (XRD) and fourier transform infrared spectroscopy (FTIR). The XRD pattern was obtained with an X'Pert PRO (Netherlands) multifunctional X-ray diffractometer using $\mathrm{CuK} \alpha$ radiation generated at $50 \mathrm{~mA}$ and $45 \mathrm{kV}$ with a scanning step of $0.03^{\circ}$ and scanning rate of $10^{\circ} \mathrm{min}^{-1}$ step scanned from 3-80 2 -theta. FTIR analysis was carried out by the FTIR Spectrometer Spectrum One (Perkin-Elmer) using the $\mathrm{KBr}$ pellet technique $(0.5 \mathrm{mg}$ powder sample mixed with 250 $\mathrm{mg}$ of $\mathrm{KBr}$ ). The pore parameters were measured by means of mercury intrusion porosimetry (MIP) on a Micromeritics Autopore IV 9500, and a maximum pressure of $228 \mathrm{MPa}(0.005 \mu \mathrm{m})$ was recommended.

\section{Results and discussion}

\subsection{Mineralogical and pore structure characterization}

\subsubsection{XRD}

The XRD patterns of the raw materials, the hardened blocks without $\mathrm{Sr}\left(\mathrm{NO}_{3}\right)_{2}$ addition and the solidified blocks 


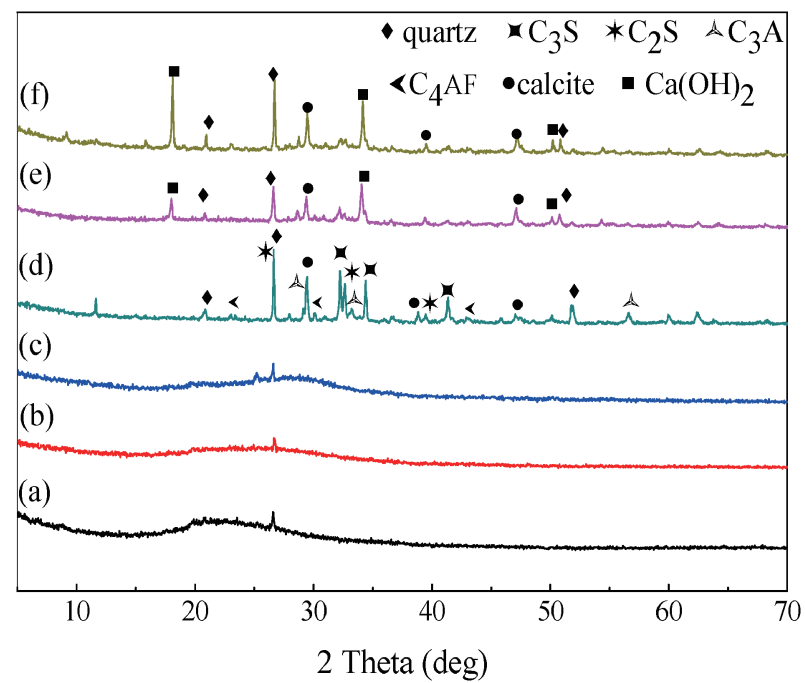

Fig. 1. XRD patterns of (a) Metakaolin; (b) Geopolymer hardened blocks; (c) Geopolymer solidified blocks; (d) Cement; (e) Cement hardened blocks; (f) Cement solidified blocks.

of strontium radionuclide are shown in Fig. 1. No crystalline phase is detected in the XRD patterns of the metakaolin, geopolymer hardened blocks and geopolymer solidified blocks [see Figs. 1(a)-1(c)]. The main crystalline phase in the XRD pattern of the Fig. 1(d) is $\mathrm{C}_{3} \mathrm{~S}, \mathrm{C}_{2} \mathrm{~S}$, $\mathrm{C}_{3} \mathrm{~A}$ and $\mathrm{C}_{4} \mathrm{AF}$, which is in accordance with the phase composition of ordinary Portland cement. Calcite and quartz in the XRD patterns [see Figs. 1(e) and 1(f)] are originated from the raw material [see Fig. 1(d)]. Meanwhile, $\mathrm{Ca}(\mathrm{OH})_{2}$ is found in the XRD patterns of the hydration products [see Figs. 1(e) and 1(f)], probably resulting from the cement hydration reactions. ${ }^{4), 6), 9)}$ In addition, calcium silicate hydrate $(\mathrm{C}-\mathrm{S}-\mathrm{H})$ is the main hydration product in most hardened cement pastes. The large surface area of C-S-H can physically adsorb a large quantity of cations. The strontium radionuclide may be mainly incorporated by physical package into the amorphous gels. ${ }^{25)-27)}$ Compared to Figs. 1(b)and 1(e), no new crystalline phase is found to be associated with the strontium radionuclide in the XRD patterns of the geopolymer and cement solidified blocks. However, geopolymer has been proven to be zeolite-like structure under the nanoscale-ordered size. ${ }^{28), 29)}$ Most of the strontium radionuclide within the solidification blocks may be incorporated into the zeolitelike three-dimensional aluminosilicate structure of geopolymer as the charge balancing cation, or chemically bonded into the amorphous phase of the geopolymer.. ${ }^{29), 30}$

\subsubsection{FTIR}

Figure 2 shows the FTIR spectra of the hardened blocks and solidified blocks. As the Fig. 2 depicts, the broad band at $3450-3425 \mathrm{~cm}^{-1}$ and the sharp band at 1650 $1630 \mathrm{~cm}^{-1}$ are characteristics of the water component of the $\mathrm{OH}$ stretching band and the chemically bonded water (H-O-H bending) respectively. ${ }^{31), 32)}$ The shift of the sharp band at $1650-1630 \mathrm{~cm}^{-1}$ in geopolymer specimens which is very sensitive for ion exchange is the evidence that the ion exchange reactions may have occurred between $\mathrm{Sr}^{2+}$

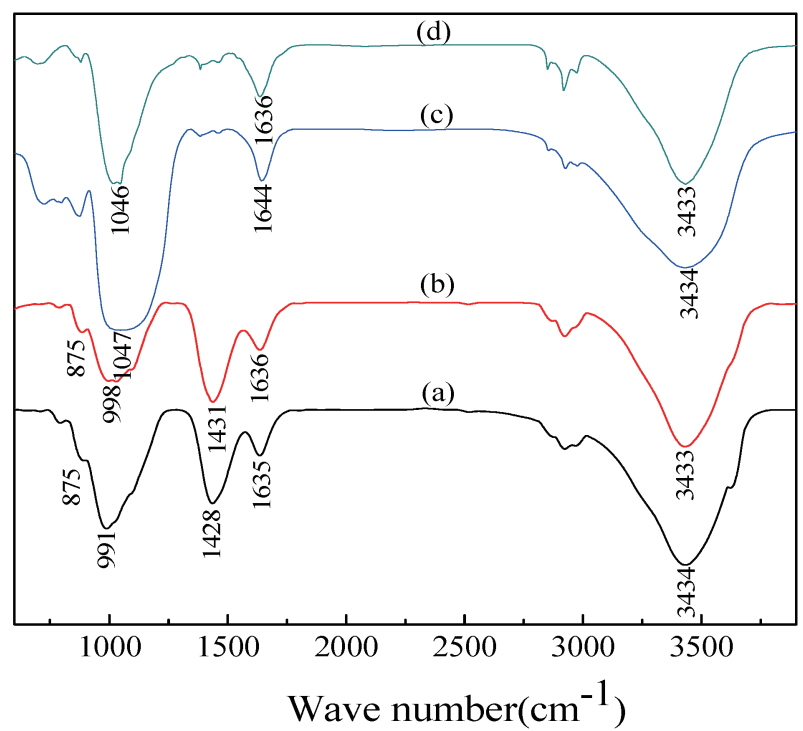

Fig. 2. FTIR spectra of (a) Cement hardened blocks; (b) Cement solidified blocks; (c) Geopolymer hardened blocks; (d) Geopolymer solidified blocks.

Table 2. Pore parameters of cement and geopolymer solidified blocks

\begin{tabular}{ccl}
\hline & Geopolymer & cement \\
\hline Porosity $(\%)$ & 9.32 & 39.70 \\
Average pore diameter $(\mathrm{nm})$ & 31.4 & 76.0 \\
Total pore surface area $\left(\mathrm{m}^{2} \mathrm{~g}^{-1}\right)$ & 5.77 & 17.23 \\
\hline
\end{tabular}

and $\mathrm{Na}^{+}$in the amorphous geopolymer gel. ${ }^{33)}$ The broad band around 1431 and $875 \mathrm{~cm}^{-1}$ respectively assign to the asymmetric stretching and out-of-plane bending of $\mathrm{CO}_{3}{ }^{2-}$ in the cement specimens, ${ }^{34)}$ indicating carbonation during the curing process or slight carbonation of the raw material, which is consistent with the XRD results. In addition, the bands around $1050-990 \mathrm{~cm}^{-1}$ corresponding to $\mathrm{Si}(\mathrm{Al})-$ $\mathrm{O}$ stretching vibration of sodium aluminosilicate hydrate gel in geopolymer and $\mathrm{C}-\mathrm{S}-\mathrm{H}$ gel in cement also can be identified in the four FTIR spectras, ${ }^{34)-36)}$ which is not only beneficial to the development of the compressive strength, but also to the immobilization of $\mathrm{Sr}^{2+}$ in the amorphous gels. ${ }^{37), 38)}$

\subsubsection{Pore structure analysis}

The pore parameters of cement and geopolymer solidified blocks are presented in Table 2. The porosity of the cement solidified blocks is significantly higher than the geopolymer solidified blocks. The average pore diameter and total pore surface area $\left(31.4 \mathrm{~nm}\right.$ and $\left.5.77 \mathrm{~m}^{2} \mathrm{~g}^{-1}\right)$ of the geopolymer blocks are much less than that of the cement blocks $\left(76.0 \mathrm{~nm}\right.$ and $\left.17.23 \mathrm{~m}^{2} \mathrm{~g}^{-1}\right)$. This may be due to the $\mathrm{C}-\mathrm{S}-\mathrm{H}$ gels occurred in cement solidified blocks, leading to the increase of average pore diameter and total pore surface area. ${ }^{39), 40)}$ Figure 3 shows a cumulative pore volume vs pore diameter of the cement and geopolymer solidified blocks by MIP. It is clear that the cumulative pore volume of the cement specimens is much larger than that of the geopolymer pastes. This proves that the geopolymer 
solidified blocks are more compact than that of the cement blocks, which may result in the higher compressive strength and better leaching resistance. ${ }^{41), 42)}$

\subsection{Leaching}

Leaching resistance is a crucial parameter to evaluate the immobilization performance of the solidified blocks.

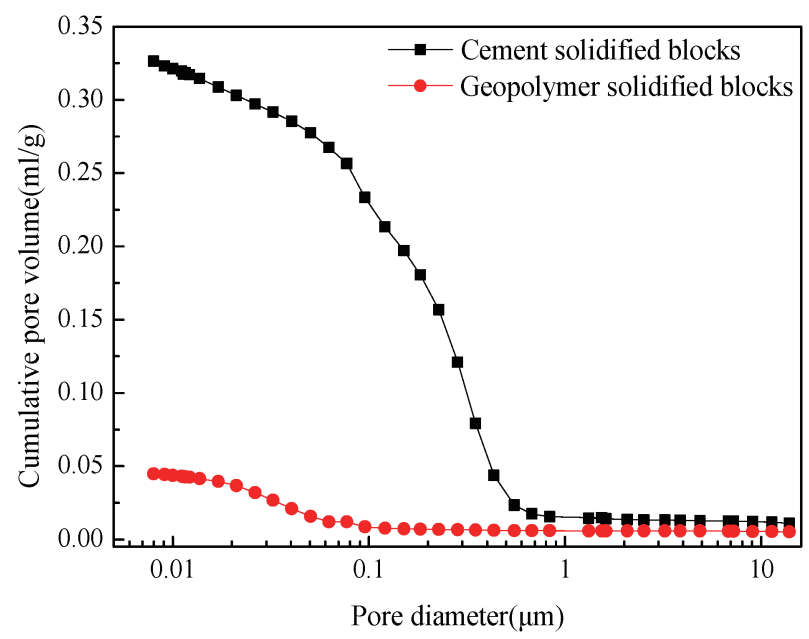

Fig. 3. Cumulative pore volume vs pore diameter in the MIP experiment for the cement and geopolymer solidified blocks.
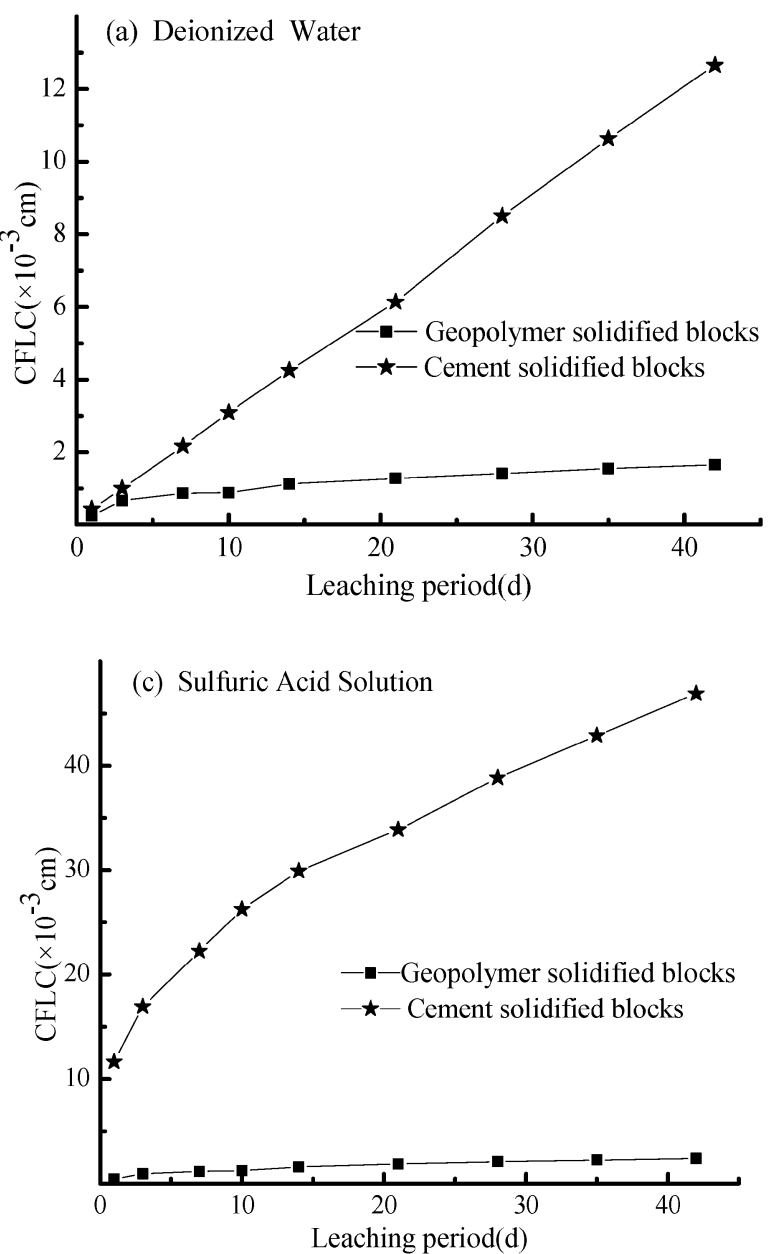

Figure 4 shows the variations of the CFLC of $90 \mathrm{Sr}^{2+}$ ions from geopolymer and cement solidified blocks which were immersed in four different extraction solutions. As seen from Fig. 4(a), geopolymer shows better leaching resistance than the cement in deionized water. This could be attributed to the more compact and dense structure of the geopolymer matrix. Moreover, the nano-scale zeolite-like structure of geopolymers with ion-exchange abilities is also beneficial for the retention of $90 \mathrm{Sr}^{2+}$ ions. ${ }^{43), 44)}$

It is worth noting that, after 42 days, the CFLC of $90 \mathrm{Sr}^{2+}$ from the geopolymer solidified blocks in magnesium sulfate solution was much less than that from the cement solidified blocks [Fig. 4(b)]. On account of the sulfate attack, which is mainly associated with the formation of gypsum and ettringite, the dissolution and decalcification of $\mathrm{C}-\mathrm{S}-\mathrm{H}$ gels occurred in cement solidified blocks, $\left.{ }^{45)}, 46\right)$ leading to the increase of capillary porosity and even greater leaching rate. On the contrary, the calcium-free geopolymers are amorphous to semicrystalline three-dimensional aluminosilicate polymers without C-S-H gels, ${ }^{47)}$ exhibiting even better performance of sulfate attack resistance. In addition, the different leaching rates of geopolymer solidified blocks in deionized water and magnesium sulfuric solution may be caused by the ion exchange between $\mathrm{Mg}^{2+}$ ions and $\mathrm{Sr}^{2+}$ ions.
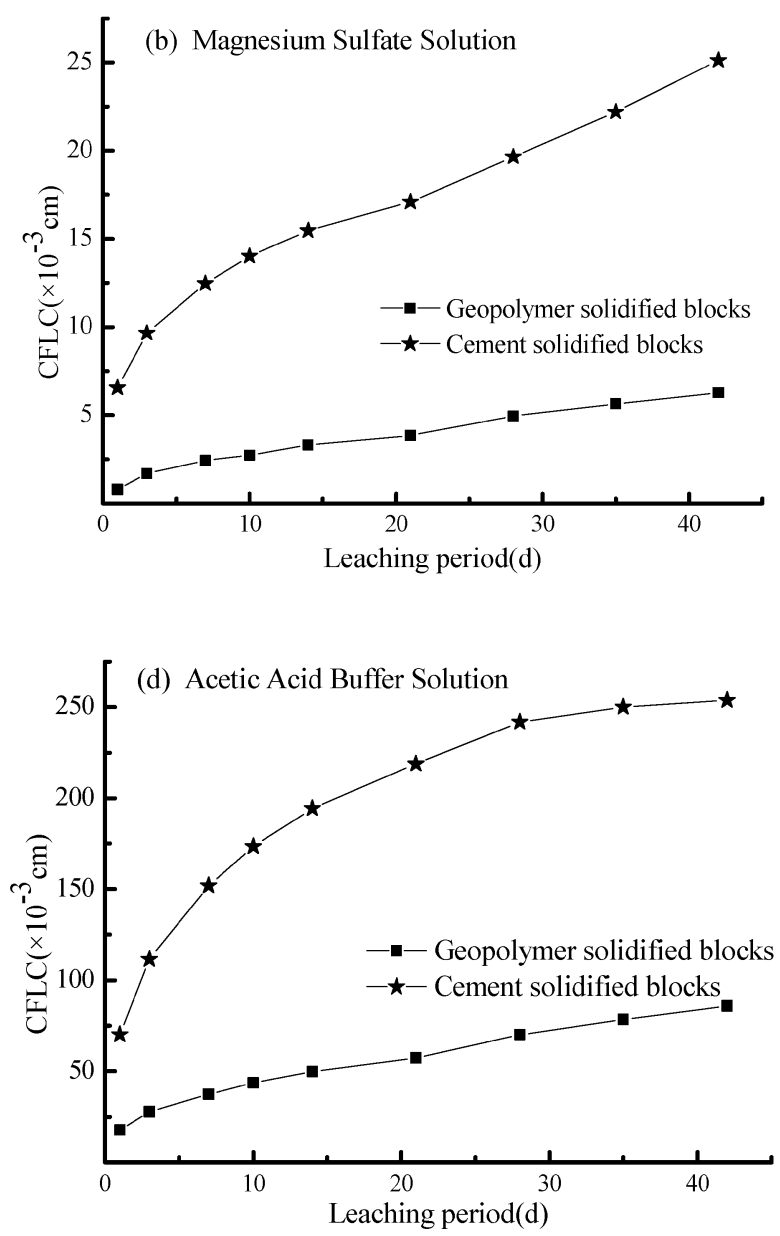

Fig. 4. CFLC of $90 \mathrm{Sr}^{2+}$ ions in four different solutions: (a) deionized water, (b) magnesium sulfate solution, (c) sulfuric acid solution, (d) acetic acid buffer solution. 
Table 3. Compressive strength of geopolymer and cement solidified blocks before and after 15 freeze-thaw cycles/MPa

\begin{tabular}{lllc}
\hline & \multicolumn{3}{c}{ Solidified bodies for $\mathrm{Sr}^{2+}$} \\
\cline { 2 - 4 } & Before & After & Loss $(\%)$ \\
\hline Geopolymer & 41.7 & 37.51 & 10 \\
Cement & 40.39 & 33.87 & 16 \\
\hline
\end{tabular}

In an acidic environment, the CFLC of $90 \mathrm{Sr}^{2+}$ ions from the cement solidified blocks were also obviously larger than those from geopolymer solidified blocks [Figs. 4(c) and 4(d)]. It is clear that the sulfuric acid solution and acetic acid buffer solution have little negative effect on the geopolymer structure, while the cement solidified blocks are completely destroyed, owing to the stable cross-linked aluminosilicate polymer structure of the geopolymer. ${ }^{47)}$ For the cement solidified blocks, the severe damage in acidic environment is attributed to the high calcium content and relatively high porosity. ${ }^{48), 49)}$ Thus, the metakaolin based-geopolymer seems to be more suitable for radioactive waste immobilization.

\subsection{Thermal stability}

\subsubsection{Freeze-thaw performance}

Solidified bodies may be buried in some areas where the temperature varies greatly between day and night. Thus, the geopolymer and cement solidified blocks are subjected to freeze-thaw cycles. The compressive strengths of the geopolymer and cement specimens before and after 15 freeze-thaw cycles are listed in Table 3. The geopolymer solidified blocks exhibit better freeze-thaw resistance than cement solidified blocks. Before freeze-thaw tests, the average compressive strength of the cement specimens was $40.39 \mathrm{MPa}$, which was $3 \%$ less than $41.7 \mathrm{MPa}$ of geopolymer matrices. After 15 freeze-thaw cycles, the geopolymer matrices showed a slight decrease in compressive strength of about 5\%, while the compressive strength of the cement specimens decreased by $16 \%$.

\subsubsection{High-temperature performance}

Radioactive decay gradually releases energy and could lead to a temperature rise of monoliths throughout the long half-life of radioactive waste. Thus, high temperature resistance tests were conducted. Figure 5 shows the changes in compressive strengths of the geopolymer and cement solidified blocks, containing $90 \mathrm{Sr}^{2+}$ ions, before and after exposure to high temperature. The compressive strengths of the geopolymer matrices showed a gentle downward trend and decreased to $32.25 \mathrm{MPa}$ after $2 \mathrm{~h}$ calcination at $1000^{\circ} \mathrm{C}$. In contrast, the high temperature damage for the cement solidified bodies was so destructive that the residual strength sharply decreased after heat treatment at $800^{\circ} \mathrm{C}$, with a drop of about $80 \%$ and almost complete loss of compressive strength (to only $5.95 \mathrm{MPa}$ ) after roasting at $1000^{\circ} \mathrm{C}$. The decomposition of the hydration products may be the primary reason for the compressive strength deterioration of the cement specimens under high temperature. ${ }^{50)}$ The excellent high temperature resistance of the geopolymer solidified blocks were mainly

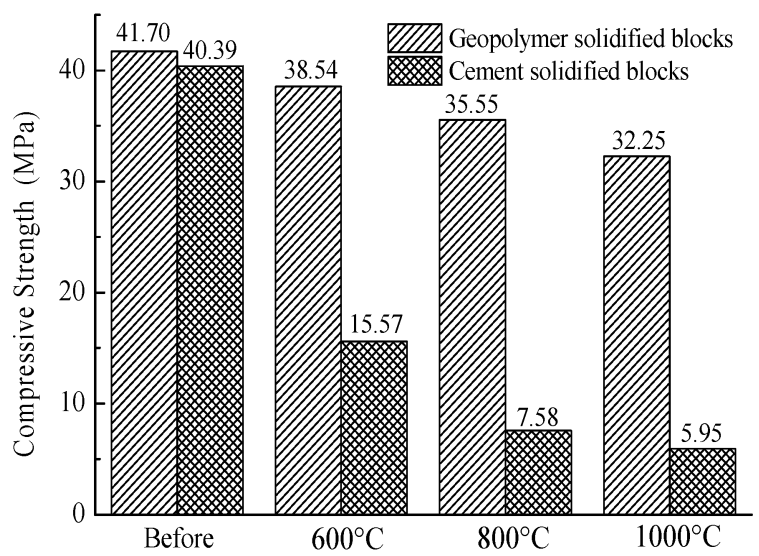

Fig. 5. Compressive strengths of geopolymer/cement solidified blocks after calcination.

due to its unique inorganic polymeric nature ${ }^{47)}$ and the formation of ceramic phases above $800^{\circ} \mathrm{C} .{ }^{51)}$

\section{Conclusions}

The metakaolin based-geopolymer exhibited much better solidification performance than the cement matrix for immobilization of simulated radionuclide $90 \mathrm{Sr}^{2+}$. To be specific, the geopolymer solidified blocks had a lower CFLC than the cement solidified blocks in deionized water, sulfuric acid solution $(\mathrm{pH}=1)$, magnesium sulfuric solution (5 wt $\% \mathrm{MgSO}_{4}$ ) and acetic acid buffer solution $(\mathrm{pH}=3.6)$. Moreover, the geopolymer solidified blocks had better thermal stability than did the cemented form. The compressive strength of the geopolymer solidification matrix measured up to $37.51 \mathrm{MPa}$ after 15 freeze-thaw cycles and up to $32.25 \mathrm{MPa}$ after $2 \mathrm{~h}$ of calcination at $1000^{\circ} \mathrm{C}$. In contrast, the cement solidified blocks lost $16 \%$ of its compressive strength after freeze-thaw cycling, and its strength was reduced to only $5.95 \mathrm{MPa}$ after roasting at $1000^{\circ} \mathrm{C}$.

Acknowledgements This work was supported by the Natural Science Foundation of China (No. 51404200), research fund from Southwest University of Science and Technology (14tdgk04, 17LZXT05, 17LZX618).

\section{References}

1) W. F. Zhang, J. F. Li and J. L. Wang, J. Nucl. Sci. Technol., 52, 1362-1368 (2015).

2) W. F. Zhang and J. L. Wang, Ann. Nucl. Energy, 101, 31-35 (2017).

3) S. B. Eskander, T. A. Bayoumi and H. M. Saleh, Prog. Nucl. Energy, 67, 1-6 (2013).

4) A. M. El-Kamash, M. R. El-Naggar and M. I. El-Dessouky, J. Hazard. Mater., 136, 310-316 (2006).

5) R. O. A. Rahman, D. H. A. Z. El Abidin and H. Abou-Shady, Chem. Eng. J., 228, 772-780 (2013).

6) A. El-Dakroury and M. S. Gasser, J. Nucl. Mater., 381, 271-277 (2008).

7) N. Yamaguchi, M. Nagaishi, K. Kisu, Y. Nakamura and K. Ikeda, J. Ceram. Soc. Jpn., 121, 847-854 (2013).

8) T. Gutberlet, H. Hilbig and R. E. Beddoe, Cement 
Concrete Res., 74, 35-43 (2015).

9) F. Chen, J. M. Gao, B. Qi and D. M. Shen, Constr. Build. Mater., 154, 849-856 (2017).

10) Y. L. Galiano, C. F. Pereira and J. Vale, J. Hazard. Mater., 185, 373-381 (2011).

11) L. Zheng, W. Wang and Y. C. Shi, Chemosphere, 79, 665-671 (2010).

12) H. Takeda, S. Hashimoto, S. Honda and Y. Iwamoto, Nippon Seramikkusu Kyokai Gakujutsu Ronbunshi, 118, 771-774 (2010).

13) S. Hayashi, T. Onuma and F. Kagaya, J. Ceram. Soc. Jpn., 125, 894-898 (2017).

14) X. Huang, R. L. Zhuang, F. Muhammad, L. Yu, Y. C. Shiau and D. W. Li, Chemosphere, 168, 300-308 (2017).

15) X. Huang, T. Huang, S. Li, F. Muhammad, G. J. Xu, Z. Q. Zhao, L. Yu, Y. J. Yan, D. W. Li and B. Jiao, Ceram. Int., 42, 9538-9549 (2016).

16) C. Kuenzel, J. F. Cisneros, T. P. Neville, L. J. Vandeperre, S. J. R. Simons, J. Bensted and C. R. Cheeseman, J. Nucl. Mater., 466, 94-99 (2015).

17) X. N. Liu, Y. Ding and X. R. Lu, Nucl. Technol., 198, 64-69 (2017).

18) N. Deng, H. An, H. Cui, Y. Pan, B. Wang, L. Q. Mao and J. P. Zhai, J. Nucl. Mater., 459, 270-275 (2015).

19) S. Donatello, C. Kuenzel, A. Palomo and A. FernandezJimenez, Cement Concrete Comp., 45, 234-242 (2014).

20) G. M. Wang, C. Zhang, B. Zhang, Q. Li and Z. H. Shui, Fire Mater., 39, 741-750 (2015).

21) D. L. Y. Kong and J. G. Sanjayan, Cement Concrete Comp., 30, 986-991 (2008).

22) D. L. Y. Kong and J. G. Sanjayan, Cement Concrete Res., 40, 334-339 (2010).

23) F. U. A. Shaikh and V. Vimonsatit, Fire Mater., 39, 174-188 (2015).

24) O. A. Abdulkareem, M. M. A. B. Abdullah, K. Hussin, K. N. Ismail and M. Binhussain, Materials, 6, 44504461 (2013).

25) M. R. Hartman, S. K. Brady, R. Berliner and M. S. Conradi, J. Solid State Chem., 179, 1259-1272 (2006).

26) C. Y. Yin, H. B. Mahmud and M. G. Shaaban, J. Hazard. Mater., 137, 1758-1764 (2006).

27) R. Spence, Crit. Rev. Env. Sci. Tec., 34, 391-417 (2004).

28) X. Cui, Y. He, L. Liu and J. Chen, MRS Commun., 1, 49-51 (2011).

29) H. Yan, X. M. Cui, M. Jin, L. P. Liu, X. D. Liu and J. Y. Chen, Micropor. Mesopor. Mat., 161, 187-192 (2012).

30) Z. Xu, Z. Jiang, D. Wu, X. Peng, Y. Xu, N. Li, Y. Qi and P. Li, Ceram. Int., 5, 4434-4439 (2016).

31) C. Villa, E. T. Pecina, R. Torres and L. Gómez, Constr.
Build. Mater., 24, 2084-2090 (2010).

32) M. A. M. Ariffin, M. A. R. Bhutta, M. W. Hussin, M. M. Tahir and N. Aziah, Constr. Build. Mater., 43, 80-86 (2013).

33) Z. H. Xu, Z. Jiang, D. D. Wu, X. Peng, Y. H. Xu, N. Li, Y. J. Qi and P. Li, Ceram. Int., 43, 4434-4439 (2017).

34) S. Boonjaeng, P. Chindaprasirt and K. Pimraksa, Appl. Clay Sci., 95, 357-364 (2014).

35) H. Zhu, Z. Zhang, F. Deng and Y. Cao, Constr. Build. Mater. 48, 124-130 (2013).

36) B. Walkley, J. L. Provis, R. S. Nicolas, M. A. Sani and J. S. J. V. Deventer, Adv. Appl. Ceram., 114, 372-377 (2015).

37) B. Guo, D. A. Pan, B. Liu, A. A. Volinsky, M. Fincan, J. $\mathrm{Du}$ and S. Zhang, Constr. Build. Mater., 134, 123-130 (2017).

38) X. Y. Zhuang, L. Chen, S. Komarneni, C. H. Zhou, D. S. Tong, H. M. Yang, W. H. Yu and H. Wang, J. Clean. Prod., 125, 253-267 (2016).

39) P. Duan, C. Yan, W. Zhou and W. Luo, Arab. J. Sci. Eng., 40, 2261-2269 (2015).

$40)$ D. L. Y. Kong, J. G. Sanjayan and K. Sagoe-Crentsil, Cement Concrete Res., 37, 1583-1589 (2007).

41) Y. Ma, J. Hu and G. Ye, Fuel, 104, 771-780 (2012).

42) O. A. Abdulkareem, M. M. A. B. Abdullah, K. Hussin, K. N. Ismail and M. Binhussain, Materials, 6, 44504461 (2013).

43) M. A. Haddad, E. Ofer-Rozovsky, G. Bar-Nes, E. J. C. Borojovich, A. Nikolski, D. Mogiliansky and A. Katz, J. Nucl. Mater., 493, 168-179 (2017).

44) B. I. El-Eswed, R. I. Yousef, M. Alshaaer, I. Hamadneh, S. I. Al-Gharabli and F. Khalili, Int. J. Miner. Process., 137, 34-42 (2015).

45) H. M. Saleh, M. E. Tawfik and T. A. Bayoumi, J. Nucl. Mater., 411, 185-192 (2011).

46) A. Allahverdi and F. Škvára, Ceramics-Silikaty, 50, 1-4 (2006).

47) E. Alvarez-Ayuso, X. Querol, F. Plana, A. Alastuey, N. Moreno, M. Izquierdo, O. Font, T. Moreno, S. Diez, E. Vazquez and M. Barra, J. Hazard. Mater., 154, 175-183 (2008).

48) T. Bakharev, Cement Concrete Res., 35, 658-670 (2005).

49) M. Y. Khalil and E. Merz, J. Nucl. Mater., 211, 141-148 (1994).

50) G. F. Peng and Z. S. Huang, Constr. Build. Mater., 22, 593-599 (2008).

51) P. G. He, D. C. Jia, M. R. Wang and Y. Zhou, Ceram. Int., 37, 59-63 (2011). 